\title{
Transport of Estrogen-induced Oxytocin Receptors in the Ventromedial Hypothalamus
}

\author{
Héctor Coirini, ${ }^{a}$ Michael Schumacher, ${ }^{D}$ Loretta M. Flanagan, and Bruce S. McEwen \\ Laboratory of Neuroendocrinology, The Rockefeller University, New York, New York 10021
}

\begin{abstract}
The modulation of oxytocin (OT) receptors (OTRs) by estrogen was investigated in the ventromedial hypothalamus by in vitro receptor autoradiography. Treatment of ovariectomized and adrenalectomized rats with various doses of estradiol benzoate (EB) increased OTR binding not only in the ventromedial nuclei of the hypothalamus (VMN), but also in the area lateral to the nuclei (IVMN). After a single injection of EB, OTRs first were induced within the ventrolateral parts of the VMN, and only hours later they appeared in the IVMN. This is consistent with the interpretation that OTRs are first induced within the estrogen-sensitive neurons of the ventrolateral VMN and then are transported laterally out of the nuclei. Two additional experiments confirmed this interpretation. First, local infusion of a low dose $(10 \mu \mathrm{g})$ of the neuronal transport inhibitor vinblastine blocked the appearance of OTRs in the IVMN but did not prevent the induction of OTRs by EB within the nuclei. Second, a knife cut placed lateral to the VMN prevented the spread of OTRs out of the nuclei. However, even after treatment with a high dose of EB $(2 \times 10 \mu \mathrm{g})$, progesterone $(P)$ was required for a maximal extension of the area covered by OTRs. Thus, the OTR is an estrogen-induced neurotransmitter receptor that is transported to its site of action, the lateral ventromedial hypothalamus, where it is modulated by $P$ and where estrogeninduced OT immunoreactivity is found.
\end{abstract}

Steroid hormone effects on brain cells involve the synthesis of specific proteins (McEwen et al., 1979; McEwen, 1988) and rapid changes in the excitability of neuronal membranes (Kelley et al., 1977; Nabekura et al., 1986). Both genomic and membrane effects of steroids interact in regulating behavioral responses such as female sexual behavior in rats (lordosis behavior) (McEwen et al., 1990; Schumacher et al., 1990). Estradiol (E) induces receptors for oxytocin (OTRs) within the ventromedial nuclei (VMN) of the rat hypothalamus (De Kloet et al., 1985; Coirini et al., 1989; Johnson et al., 1989a), most likely by activating the synthesis of new receptors (Nissenson et al., 1978; Johnson et al., 1989b). Progesterone (P) then rapidly mod-

\footnotetext{
Received Jan. 29, 1991; revised May 16, 1991; accepted May 29, 1991.

This work was supported by NIH Grant NS07080 (B.S.M.). H.C. was supported by a fellowship of the Consejo Nacional de Investigaciones Científicas y Técnicas de la República Argentina. M.S. was supported by NIH Grant TW04103 and by a grant from NATO.

Correspondence should be addressed to Dr. Bruce S. McEwen, Laboratory of Neuroendocrinology, The Rockefeller University, 1230 York Avenue, New York, NY 10021.

a Present address: Department of Biochemistry, School of Medicine, University of Buenos Aires, Paraguay 2155, $5^{\circ}$ Piso, Buenos Aires 1121, Argentina.

' Present address: Laboratoire Hormones, INSERM U33, Rue du Général Leclerc 78, 94275 Bicêtre Cedex, France.

Copyright (C 1991 Society for Neuroscience $0270-6474 / 91 / 113317-08 \$ 05.00 / 0$
}

ulates the estrogen-induced OTRs by acting directly on the neuronal membrane (Schumacher et al., 1990a). The modulation of OTR binding by $\mathrm{P}$ is necessary for the facilitation of lordosis behavior by oxytocin (OT) and may correspond to an activation of the OTR (Schumacher et al., 1989, 1990a).

E increases OTR binding not only within the VMN, but also within the area lateral to the nuclei (IVMN), where OT immunoreactivity is present in large fiber tracts and terminals (Schumacher et al., 1989). It is unknown whether the increased area covered by OTRs is due to estrogen-induced OTRs within the few estrogen-sensitive cells that surround the VMN (Pfaff and Keiner, 1973; Brown et al., 1989), or to OTRs induced within the VMN that are then transported toward OT-containing terminal fields located outside the boundaries of the VMN. There are observations in favor of the latter mechanism. First, the density of OTRs is highest in the ventrolateral subdivision of the VMN (Johnson et al., 1989b), where estrogen-concentrating cells are most abundant (Pfaff and Keiner, 1973). Second, VMN neurons have long axons and dendrites that extend into the lateral ventromedial hypothalamus and along which OTR could be transported to the IVMN (Millhouse, 1973). After their transport, once in contact with OT terminals, the estrogen-induced OTRs would then be ready for activation by $P$.

The neuronal transport of estrogen-induced proteins is involved in the facilitation of lordosis behavior (Harlan et al., 1982; Meyerson, 1982). Recently, such a protein has been identified. Within the ventromedial hypothalamus, $\mathrm{E}$ induces a phospholipase (PLC- $\alpha$ or HIP-70) that is transported to the midbrain central gray and that may be involved in the facilitation of lordosis behavior (Mobbs et al., 1988, 1990a,b). However, an estrogen-induced protein that is transported out of the VMN and that is subsequently modulated by $P$ has not been identified so far. Such a protein could mediate the interactions between $E$ and $P$ in activating female mating.

Understanding the mechanisms by which $E$ induces P-sensitive OTRs close to OT terminals within the lateral ventromedial hypothalamus would not only allow a better understanding of the interactions between $E$ and $P$ in facilitating female sexual behavior, but it would also explain the apparent mismatch between the distribution of estrogen-induced OTR, the density of which is highest within the VMN, and OT-immunoreactive fibers that are present in the area lateral to the nuclei (Schumacher et al., 1989).

To determine whether the estrogen-induced OTRs are transported out of the VMN, we first examined the time course of their appearance inside and outside the VMN after treatment with estradiol benzoate (EB). Then, we used either the neurotoxin vinblastine or a lateral knife cut to interrupt the continuity of fibers in the lateral ventromedial hypothalamus with cell bodies of origin located in the VMN. 


\section{Materials and Methods}

\section{Animals and treatments}

Female Sprague-Dawley rats (250-300 gm) were housed three animals per cage in an inverse light/dark cycle (lights on at 8 P.M., lights off at 10 A.M.) throughout all experiments with food and drinking water ad libitum. Females were ovariectomized (OVX) or OVX and adrenalectomized (ADX) under methoxyflurane (Metofane) anesthesia. When rats were ADX, their drinking water was replaced by $0.9 \%$ saline. The adrenal glands were removed in most of the experiments because they are an important source of progesterone (Mann and Barraclough, 1973). Hormones were always injected subcutaneously at the end of the light phase (between 9:30 A.M. and 10 A.M.).

Experiment $i$. Dose-dependent effects of estrogen. Thirty-six rats were OVX and ADX. Two days later, they were injected with different amounts of EB [1 $\mu \mathrm{g}(n=8), 5 \mu \mathrm{g}(n=4), 10 \mu \mathrm{g}(n=8), 20 \mu \mathrm{g}(n=4)$, or $50 \mu \mathrm{g}$ $(n=4)$ ] dissolved in sesame oil or with vehicle alone (controls, $n=8)$. Forty-eight hours after the injection, animals were killed and brains were sampled for OTR autoradiography. Uteri were weighed to the nearest milligram and collected for the assay of myometrial OTR binding.

Experiment ii. Effects of progesterone. Seventeen OVX and ADX rats were distributed between three experimental groups. Two days after surgery, animals were injected with $10 \mu \mathrm{g}$ of EB once $(n=5)$ or on two successive days $(2 \times 10 \mu \mathrm{g} \mathrm{EB} ; n=12)$. Forty-eight hours later, animals of the first group and five females of the $2 \times 10 \mu \mathrm{g}$ EB group were injected with vehicle. The remaining seven animals of the second group were injected with $0.5 \mathrm{mg}$ of $\mathrm{P}$ dissolved in $100 \mu \mathrm{l}$ of propylene glycol $(\mathrm{EB}+\mathbf{P}$ group). Four hours after the last injection, brains were sampled for OTR autoradiography.

Experiment iii. Time-dependent effects of estrogen. Twenty rats were OVX and ADX. Two days later, animals were injected with $10 \mu \mathrm{g}$ of EB dissolved in sesame oil. Rats were killed by decapitation within 1 $\min (0 \mathrm{hr})$ or $6,12,24$, or $48 \mathrm{hr}$ after the injection of EB $(n=4$ per group). Uteri were weighed to the nearest milligram and collected for the assay of myometrial OTR binding.

Experiment iv. Effects of vinblastine. Seventeen females were anesthetized with a mixture of ketamine and PromAce (ketamine, $60 \mathrm{mg} /$ $\mathrm{kg}$; PromAce, $12 \mathrm{mg} / \mathrm{kg}$; Fort Dodge) and stereotaxically implanted with bilateral guide cannulas ( 22 gauge). The tips of the cannulas were located $1 \mathrm{~mm}$ above the injection sites (dorsolateral to the posterior VMN; coordinates: $3.2 \mathrm{~mm}$ posterior from bregma, $0.9 \mathrm{~mm}$ lateral from midline, $8.2 \mathrm{~mm}$ vertical from the top of the skull, with the incisor bar set $8 \mathrm{~mm}$ below the intra-aural line). The infusion site was located above the lateral border of the VMN so that during infusion, both the cell body region of the VMN and the area lateral to the nuclei were equally exposed to vinblastine. A dummy cannula was kept in the guide cannulas, except during infusions. One week after the stereotaxic surgery, the animals were OVX and ADX. Two days later, different doses of vinblastine (10 or $20 \mu \mathrm{g}$ dissolved in $0.9 \%$ saline; Sigma) were infused unilaterally into the ventromedial hypothalamus via an internal cannula (28 gauge) that extended $1 \mathrm{~mm}$ below the tip of the guide cannula. The contralateral side of the ventromedial hypothalamus (control side) was infused with saline alone. The inner cannula was connected by polyethylene tubing to a $1 \mathrm{cc}$ glass syringe driven by a syringe pump (Sage Instruments, model $341 \mathrm{~A}$ ). Volumes infused into each side were $1 \mu \mathrm{l}$ during $2 \mathrm{~min}$. During the infusion, rats were restrained by hand. Twentyfour hours after infusion, rats were injected with $10 \mu \mathrm{g}$ of ED. To determine whether the unilateral infusion of vinblastine affected the binding of the iodinated OTA ligand ( ${ }^{125}$ I-OVTA) in the contralateral side, four additional females were bilaterally infused only with saline.

Forty-eight hours after EB, animals were killed and brains were sampled for the autoradiography of OTR. The locations of the cannulas were verified on sections stained with cresyl violet.

We used vinblastine instead of colchicine to block the transport of OTR because vinblastine interacts more selectively with microtubules (Hanson and Edström, 1978). Vinblastine was administered $24 \mathrm{hr}$ before the injection of EB because vinca alkaloids like vinblastine affect microtubules and neuronal transport mechanisms only hours after their administration, but their effects are long lasting (O'Donohue et al., 1979; Chan et al., 1980; Harlan et al., 1982). Moreover, rats show a decreased vinblastine toxicity after being exposed to estrogen (Cutts, 1968; Lessman, 1987; Wheeler et al., 1987).

Experiment v. Effects of lateral knife cuts. One week after OVX $(n=$
12), lateral knife cuts were made adjacent to the posterior part of the right VMN with the flattened and sharpened end of a 28-gauge cannula (100 $\mu \mathrm{m}$ thick, $625 \mu \mathrm{m}$ widc, and $1250 \mu \mathrm{m}$ high) (coordinates: $2.7 \mathrm{~mm}$ posterior from bregma, $0.9 \mathrm{~mm}$ lateral from midline, $10.3 \mathrm{~mm}$ vertical from the top of the skull, with the incisor bar set $2.3 \mathrm{~mm}$ below the intra-aural line). Hormone treatment started the next day. Rats were injected on two successive days with $10 \mu \mathrm{g}$ of EB. Forty-eight hours after the last injection, brains were sampled for OTR autoradiography. Knife cuts were examined under a microscope on stained sections. Only 6 out of the 12 brains were used for the study of OTR binding. For these brains, cuts were adjacent to the VMN and the area lateral to the right VMN was not damaged.

\section{Quantitative autoradiography of oxytocin receptors}

Brains were quickly removed, frozen on dry ice, and stored at $-70^{\circ} \mathrm{C}$. OTR binding in the ventromedial hypothalamus was quantified by the tcchnique of in vitro receptor autoradiography (Elands et al., 1987; Schumacher et al., 1990a). Brain slices (20 $\mu \mathrm{m}$ thick) corresponding to coronal plates $30-31$ of the stereotaxic atlas of Paxinos and Watson (1986) were cut in a cryostat, thaw mounted onto gelatin-subbed glass slides ( $1 \%$ gelatin, $0.05 \%$ chromium potassium sulfate), and dried overnight in a dessicator at $-10^{\circ} \mathrm{C}$ under partial vacuum. They were then stored at $-70^{\circ} \mathrm{C}$. The day of assay, the slide-mounted brain sections were thawed, dried at room temperature (RT) for $30 \mathrm{~min}$, and preincubated for $30 \mathrm{~min}$ at RT in $50 \mathrm{~mm}$ Tris buffer (Trizma base, pH 7.4; Sigma). Brain sections were then incubated for $60 \mathrm{~min}$ in $50 \mathrm{~mm}$ Tris buffer containing $10 \mathrm{mM} \mathrm{MgCl}, 0.1 \%$ bovine serum albumin, $0.05 \%$ bacitracin ( $\mathrm{pH} 7.4$ ), and $25-30 \mathrm{pM}$ specific iodinated OTR ligand OVTA ( $\left.{ }^{125} \mathrm{I}-\mathrm{D}\left(\mathrm{CH}_{2}\right)^{5},[\mathrm{Tyr}(\mathrm{Me})]^{2}, \mathrm{Thr}^{4}, \mathrm{Tyr}-\mathrm{NH}_{2}{ }^{9}\right)-\mathrm{OVT}$; New England Nuclear; specific activity, $2200 \mathrm{Ci} / \mathrm{mmol}$ ) (Elands et al., 1987). Nonspecific binding was detcrmincd by adding $2 \mu \mathrm{M}$ unlabeled OT (Peninsula) to the incubation medium. The incubation was ended by two $3 \mathrm{~min}$ washes in ice-cold buffer ( $50 \mathrm{~mm}$ Tris, $10 \mathrm{~mm} \mathrm{MgCl}_{2}$ ) followed by a rapid dip in ice-cold double-distilled water. Slides were rapidly air dried.

Autoradiograms were generated by apposing ${ }^{125}$ I-OVTA-labeled sections to tritium-sensitive film ( ${ }^{3} \mathrm{H}$-Hyperfilm, Amersham) for $4 \mathrm{~d}$ at room temperature. Binding of ${ }^{225}$ I-OVTA to hypothalamic OTR was quantified by using a computer-assisted densitometer (DUMAs Version 2). The measured relative optical densities were converted to $\mathrm{fmol} / \mathrm{mg}$ protein by using a standard curve derived from coexposed iodinated $20-\mu \mathrm{m}$-thick brain paste sections. The protein content of these sections was determined by the method of Bradford (1976). Binding within the VMN and surrounding area was quantified by apposing adjacent stained sections (cresyl violet) to the autoradiograms. The area covered by OTR within the ventromedial hypothalamus was measurcd by quantifying the number of pixels with optical densities higher than the mean optical density of nonspecific binding in adjacent sections. The number of pixels was then converted to $\mathrm{mm}^{2}$ ( 250 pixels $\left./ \mathrm{mm}^{2}\right)$.

To measure OTR binding in the uterus, a paste was prepared from the whole uterus of each animal at $4^{\circ} \mathrm{C}$, compressed in a plastic tube of $5 \mathrm{~mm}$ diameter, and then frozen at $-70^{\circ} \mathrm{C}$. After removing the tube, $20-\mu \mathrm{m}$-thick sections were cut in a cryostat (38 $\mu \mathrm{g}$ of protein per section as determined by the method of Bradford, 1976). Four sections of each frozen uterus paste were thaw mounted onto subbed slides and were then incubated in the presence of 27 pM ${ }^{125}$ I-OVTA with or without 2 $\mu \mathrm{M}$ OT. The assay conditions were the same as those described above for the brain sections except that after drying, the labeled uterus sections were wiped from the slides with wet filter paper (four sections per sample $=152 \mu \mathrm{g}$ of protcins; two samples per data point). Binding was detcrmined by scintillation counting, and counts were corrected for counting efficiency.

\section{Statistics}

Between multiple treatment groups, data were compared by one-way ANOVA followed by Duncan's multiple-range tests. Comparisons between two experimental groups were made by independent two-tailed $t$ tests.

\section{Results}

Experiment $i$. Dose-dependent effects of estrogen in ventromedial hypothalamus and uterus

Because estrogen treatments induce OTR with similar pharmacological characteristics in both VMN (Johnson et al., 
Table 1. Effect of EB on specific ${ }^{125}$ I-OVTA binding to uterine tissue and uterus weights

\begin{tabular}{cll} 
Measure & $\begin{array}{l}\text { Binding } \\
\text { (fmol/mg protein) }\end{array}$ & $\begin{array}{l}\text { Uteri weight } \\
(\mathrm{mg}, \text { mean } \pm \mathrm{SD})\end{array}$ \\
\hline $\begin{array}{c}\text { Dose } \\
0 \mu \mathrm{g}\end{array}$ & $2.0 \pm 0.2^{a}$ & \\
$1 \mu \mathrm{g}$ & $25 \pm 4.0^{b}$ & $170 \pm 12^{a}$ \\
$10 \mu \mathrm{g}$ & $24 \pm 2.0^{b}$ & $324 \pm 10^{b}$ \\
ANOVA & $p \leq 0.001, F=24.0$ & $346 \pm 29^{b}$ \\
Time & & $p \leq 0.001, F=29.0$ \\
$0 \mathrm{hr}$ & $2.0 \pm 0.2^{a}$ & \\
$6 \mathrm{hr}$ & $11.7 \pm 1^{b}$ & $186 \pm 11^{a}$ \\
$12 \mathrm{hr}$ & $16.5 \pm 2^{b}$ & $313 \pm 19^{b}$ \\
$24 \mathrm{hr}$ & $26.5 \pm 3^{c}$ & $293 \pm 27^{b}$ \\
$48 \mathrm{hr}$ & $24.5 \pm 2^{c}$ & $319 \pm 19^{b}$ \\
ANOVA & $p \leq 0.001, F=28.0$ & $347 \pm 29^{b}$ \\
& & $p \leq 0.001, F=7.7$ \\
\hline
\end{tabular}

Oxytocin rcceptor binding was quantified in the uterus of OVX-ADX rats $48 \mathrm{hr}$ after a single injection of different doses of EB or different times after a single injection of $1 \mu \mathrm{g}$ of $\mathrm{EB}$. Different letters close to the results denote statistical differences at least at the 0.05 level by Duncan tests.

1989a,b) and uterus (Fuchs et al., 1983; Soloff et al., 1983), we compared the effects of EB on OTR binding in both structures. OTRs in the VMN are very sensitive to the inductive effects of estrogen. ${ }^{225}$ I-OVTA binding was significantly increased $48 \mathrm{hr}$ after a single injection of only $1 \mu \mathrm{g}$ of $\mathrm{EB}$, and $5 \mu \mathrm{g}$ of EB were sufficient to induce maximal receptor binding (Fig. 1). However, treatment with EB increased ${ }^{125}$ I-OVTA binding not only within the VMN, but also in the area lateral to the nuclei (IVMN). Whereas in control animals the binding of ${ }^{125}$ I-OVTA was low and restricted to the ventrolateral parts of the VMN, EB treatment induced high levels of OTR both inside and outside the VMN. As a consequence, estrogen treatment increased not only OTR binding, but also the area covered by the receptors (Fig. 1). The extension of OTR binding was largest after $10 \mu \mathrm{g}$ of EB for $48 \mathrm{hr}$.

Uteri of control animals were small and contained only few $\mathrm{OT}$ binding sites. After treatment with $1 \mu \mathrm{g}$ of $\mathrm{EB}$, uteri weights were doubled in comparison to controls, and the number of OTR bindings was increased 12-fold to maximal levels (Table $1)$.

\section{Experiment ii. Effects of progesterone}

Results of the previous experiment show that EB increases in a dose-dependent manner the area covered by OTRs within the ventromedial hypothalamus. However, we have recently reported that $P$ further expands the OTR field in estrogen-primed females (Schumacher et al., 1989, 1990a). This observation raises the question of whether $P$ is required for a maximal extension of OTR binding, cren after treatment with a high dose of EB. To examine this problem, females were injected once or on two successive days with $10 \mu \mathrm{g}$ of EB (low and high estrogen priming, respectively). A third group was injected twice with $10 \mu \mathrm{g}$ of EB followed by $0.5 \mathrm{mg}$ of $P$.

The extent of ${ }^{125}$ I-OVTA binding was similar in females that received a single or two successive injections of $10 \mu \mathrm{g}$ of EB (1 $\times 10 \mu \mathrm{g} \mathrm{EB}, 1.89 \pm 0.19 \mathrm{~mm}^{2} ; 2 \times 10 \mu \mathrm{g} \mathrm{EB}, 2.0 \pm 0.17 \mathrm{~mm}^{2}$; mean \pm SD). However, $P$ further increased the area covered by OTR in rats injected twice with estrogen $(2 \times 10 \mu \mathrm{g} \mathrm{EB}+\mathrm{P}, 2.80$ $\pm 0.16 \mathrm{~mm}^{2}$; mean $\pm \mathrm{SD} ; p \leq 0.01$ when compared to females primed with EB alone by Duncan's multiple-range tests). Thus,
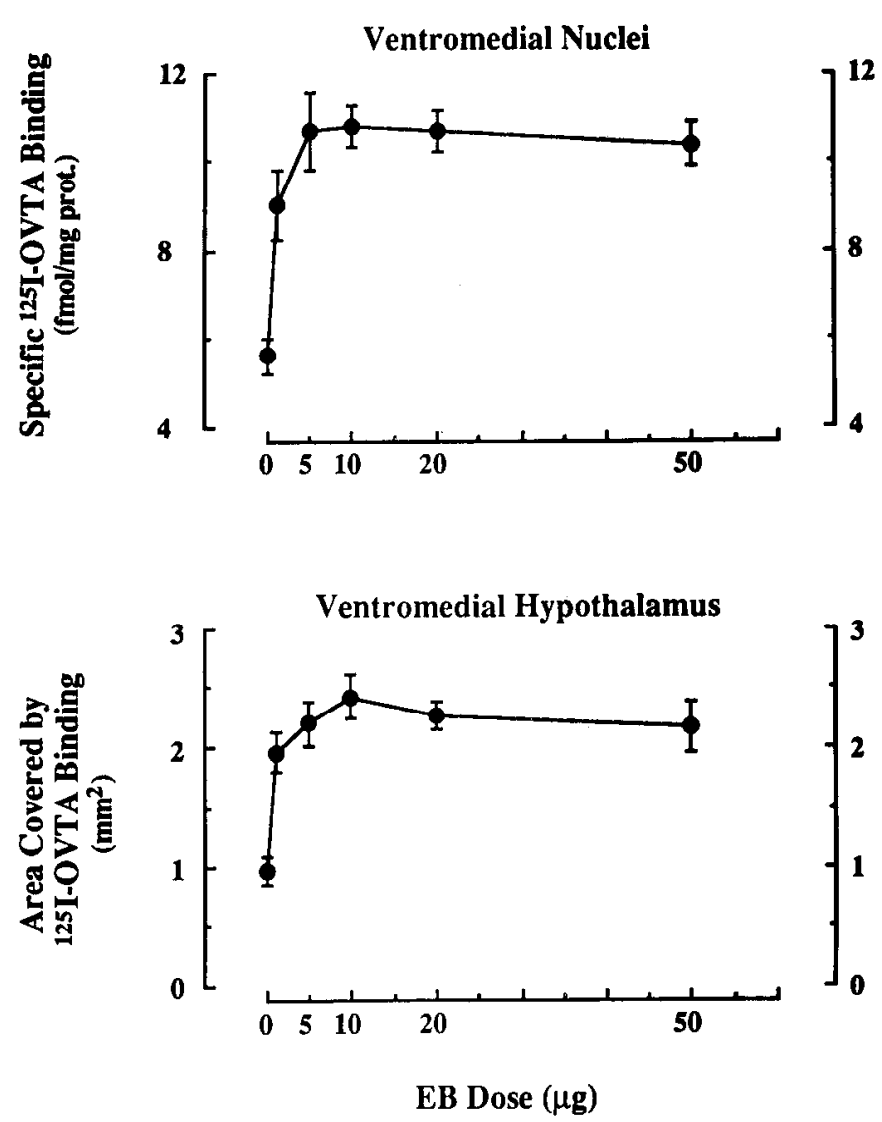

Figure 1. Treatment of OVX and ADX rats with different doses of EB increased the specific binding of ${ }^{125} \mathrm{I}$-OVTA in the VMN of the hypothalamus (top: $p \leq 0.001, F=17.9, \mathrm{df}=5$ ) and the area covered by OTRs within the ventromedial hypothalamus, including the VMN (bottom: $p \leq 0.001, F=66.6, \mathrm{df}=5$ ). Both binding and area were significantly increased by $1 \mu \mathrm{g}$ of EB ( $p \leq 0.01$ by Duncan's multiplerange test) but were highest after the injection of $5 \mu \mathrm{g}$ of EB (binding) or $10 \mu \mathrm{g}$ of EB (in each case, $p \leq 0.05$ when compared to the $1 \mu \mathrm{g}$ dose by Duncan's multiple-range test). Error bars represent mean \pm SEM.

even when estrogen priming is high, $\mathrm{P}$ is required for a maximal extension of OTR binding.

\section{Experiment iii. Time-dependent effects of estrogen in ventromedial hypothalamus and uterus}

OTR binding and the area covered by these receptors are highest within the ventromedial hypothalamus $48 \mathrm{hr}$ after a single injection of $10 \mu \mathrm{g}$ of EB (Fig. 1). However, EB not only induces OTR within the VMN, but also in the IVMN. This observation may be explained as an induction by estrogen of OTR both in cells of the VMN and in cells outside the nuclei. Alternatively, OTR may be induced exclusively within the estrogen-sensitive neurons of the ventrolateral VMN and may then be transported toward OT-containing terminal fields located outside the boundaries of the VMN. To distinguish between these two possibilities, we studied the time course of the modulation of OTR binding by estrogen. If OTRs are induced in the VMN cell bodies and subsequently transported to the IVMN, the binding should first increase within the VMN and then progressively in the IVMN as transport occurs.

OTR binding was quantified within the ventromedial hypothalamus immediately $(0 \mathrm{hr})$ or $6,12,24$, or $48 \mathrm{hr}$ after a single injection of $10 \mu \mathrm{g}$ of EB. Within the VMN cell body region, the binding of ${ }^{125}$ I-OVTA significantly increased between 0 and 6 

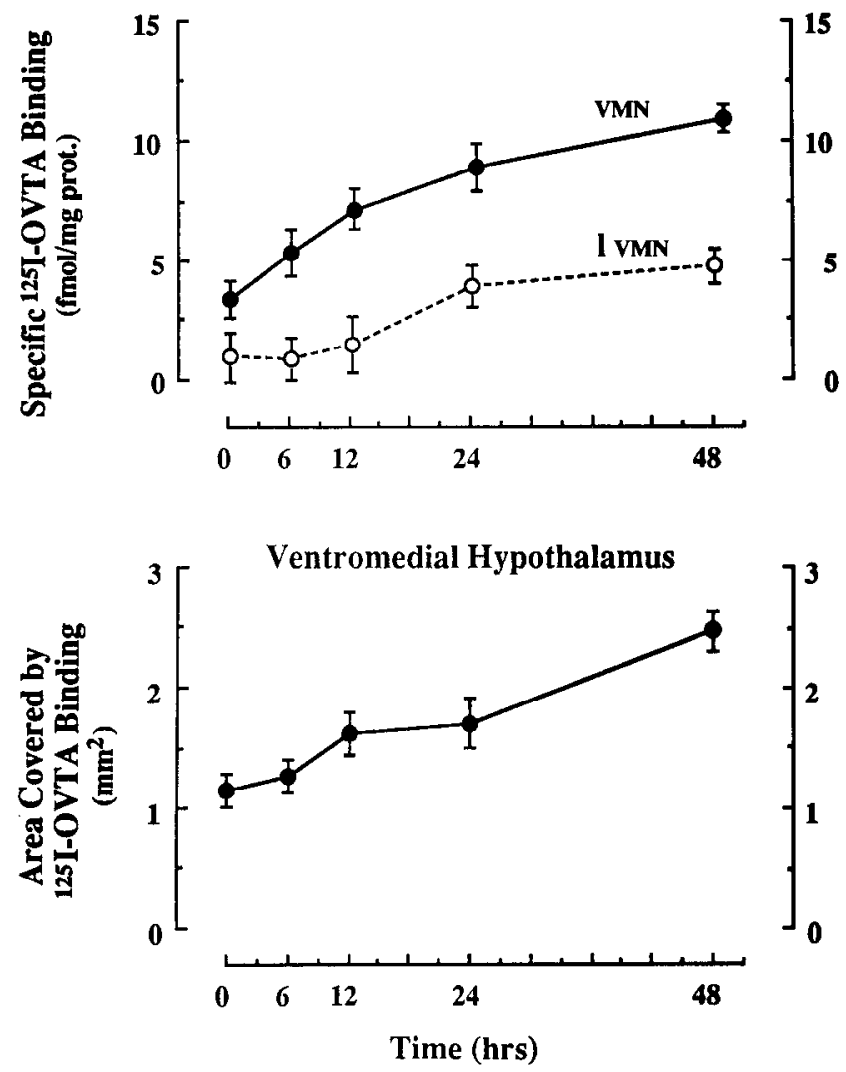

Figure 2. Specific binding of ${ }^{125}$ I-OVTA in the VMN and in the area surrounding these nuclei (IVMN) (top) and area covered by OTRs within the ventromedial hypothalamus, including the VMN (bottom). Brains were sampled for the quantitative autoradiography of OTRs different times after a single injection of $10 \mu \mathrm{g}$ of EB. Within the cell body region of the VMN, the binding of ${ }^{125}$ I-OVTA was already significantly increased $6 \mathrm{hr}$ after EB and then further increased until reaching its highest levels after $48 \mathrm{hr}(p \leq 0.01$ for each time when compared to the previous one). By contrast, in the IVMN, binding significantly increased only between 12 and $24 \mathrm{hr}(p \leq 0.001)$ and then further increased between 24 and $48 \mathrm{hr}(p \leq 0.05)$. The area covered by OTRs within the ventromedial hypothalamus significantly increased between 6 and $12 \mathrm{hr}(p$ $\leq 0.01)$ and between 24 and $48 \mathrm{hr}(p<0.01)$ (Duncan's multiple-range tests after one-way ANOVA). Error bars represent mean \pm SEM.

hr but was highest only $48 \mathrm{hr}$ after EB (Fig. 2). During the first $6 \mathrm{hr}$, OTR binding was primarily limited to the VMN and only significantly increased in the IVMN between 12 and $24 \mathrm{hr}$ (Fig. 2 ). In contrast to the progressive increase in binding density, the area covered by OTR within the ventromedial hypothalamus, including the VMN, increased in a biphasic manner. A first significant increase occurred between 6 and $12 \mathrm{hr}$, and a second increase occurred between 24 and $48 \mathrm{hr}$. As most of the OTR binding was still confined to the VMN after $12 \mathrm{hr}$, the first increase in area mainly corresponded to an extension of OTR binding within the VMN cell body region. The second significant increase in area occurred after OTR binding in the IVMN approached maximal levels (Fig. 2). The temporal progression of OTR binding is shown by representative autoradiograms in Figure 3. The effect of the ovarian steroid hormones on the area covered by OTRs in the ventromedial hypothalamus (experiments ii and iii) is summarized in Figure 4.

In the uterus, OTR levels increased between 0 and $6 \mathrm{hr}$ and were highest $24 \mathrm{hr}$ after EB. The weights of the uteri were already maximal $6 \mathrm{hr}$ after EB injection (Table 1).

\section{Experiment iv. Effects of vinblastine}

One interpretation of these results is that EB induces OTRs in the VMN and that these receptors are then transported laterally along axons or dendrites. Alternatively, OTR could be induced by EB with a different time course in the VMN and IVMN. To determine whether the estrogen-induced OTRs are transported, we infused two different doses (10 or $20 \mu \mathrm{g}$ ) of the neuronal transport inhibitor vinblastine into the right side of the ventromedial hypothalamus. The binding of ${ }^{125}$ I-OVTA was quantified within the ventrolateral (vVMN) and dorsal (dVMN) subdivisions of the VMN and within the IVMN. The unilateral infusion of 10 or $20 \mu \mathrm{g}$ of vinblastine did not affect the binding of ${ }^{125} \mathrm{I}$ OVTA in the contralateral ventromedial hypothalamus. The area covered by OTRs in the side contralateral to the vinblastine infusion site $\left(1.90 \pm 0.22 \mathrm{~mm}^{2}\right)$ did not differ from any sides of the ventromedial hypothalamus of rats that were infused with saline alone (left side, $1.87 \pm 0.18 \mathrm{~mm}^{2}$; right side, $2.0 \pm 0.30$ $\mathrm{mm}^{2}$; mean + SEM).

On the average, in a total of six rats, the low dose of vinblastine $(10 \mu \mathrm{g})$ significantly decreased the binding of ${ }^{125}$ I-OVTA within the dorsal and ventral parts of the VMN when compared to the control side, and it prevented the appearance of OTR binding within IVMN (vVMN: control, $17.4 \pm 1.4$; vinblastine, $7.0 \pm$ 1.8**; dVMN: control, $6.3 \pm 1.1$; vinblastine, $2.8 \pm 0.9^{* *}$; IVMN: control, $8.7 \pm 1.4$; vinblastine, $0.9 \pm 0.3^{* * * ;} \mathrm{fmol} / \mathrm{mg}$ proteins, mean $\pm \mathrm{SEM}$; ${ }^{* *}, p \leq 0.001 ; * *, p \leq 0.01$, when compared to the corresponding control side by paired $t$ tests). However, in three out of the six rats that were infused with 10 $\mu \mathrm{g}$ of vinblastine, the binding of ${ }^{125}$ I-OVTA was not decreased significantly within the VMN but was absent in the IVMN (Fig. $5)$. By contrast, the high dose of vinblastine $(20 \mu \mathrm{g})$ completely blocked the induction of OTRs by EB in both the VMN and IVMN (results not shown).

\section{Experiment v. Effects of lateral knife cuts}

Although a low dose of vinblastine tended to reduce the efficiency of EB in inducing OTR within the VMN, it completely blocked the appearance of OT binding sites outside the nuclei. Furthermore, in half of the animals, vinblastine did not interfere with OTR binding in the VMN while still preventing the appearance of receptors in the area lateral to the nuclei (Fig. 5). These results are interpreted as indicating that OTRs are induced by estrogen within the cell body region of the VMN and are then transported outside the nuclei along axons or dendrites by a mechanism that requires intact microtubules. They also indicate that the transport of UTR into the IVMN is more sensitive to vinblastine than the induction of OTR in the VMN. If this interpretation is correct, cutting the latcral projections of VMN neurons should interrupt the transport of receptors outside the VMN, and as a consequence should prevent the appearance of receptors in the IVMN. This was indeed the case. A knife cut adjacent to the right VMN did not affect the induction of OTR within the VMN but prevented the appearance of OTR outside the nucleus (Fig. 6).

\section{Discussion}

Present results show that EB induces OTRs within the VMN and that these receptors are then transported into the area lateral to the nuclei (IVMN), where OT fibers and terminals are present (Schumacher et al., 1989, 1990b). After a single injection of EB, OTRs are first induced within the VMN, and only hours later, 


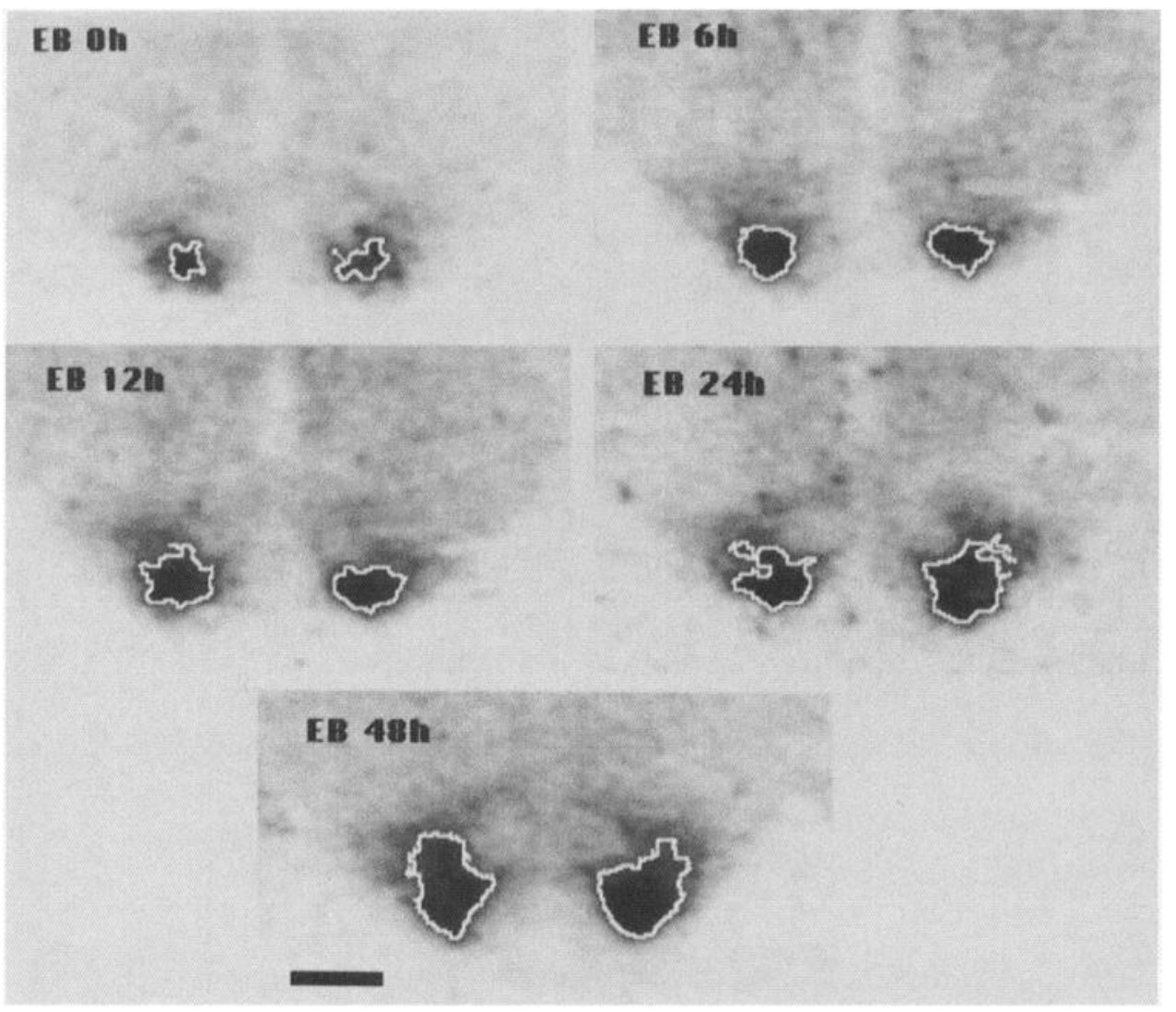

Figure 3. Representative autoradiograms of ${ }^{125}$ I-OVTA binding in the ventromedial hypothalamus. Brains were sampled for quantitative receptor autoradiography different times after a single injection of $10 \mu \mathrm{g}$ of EB. The drawn boundaries within the ventromedial hypothalamus show the extension of the area covered by the OTRs. Scale bar, $1.5 \mathrm{~mm}$. they appear in the IVMN. Moreover, the local administration of the neuronal transport inhibitor vinblastine or a knife cut placed lateral to the VMN prevents the appearance of OTR in the IVMN but does not block the induction of OTRs by EB in the VMN. That estrogens induce OTRs by acting at the level of the VMN has been demonstrated recently. When applied locally to the VMN, small amounts of $E$ induce OTR within the nuclei (M. Schumacher, H. Coirini, and B. S. McEwen, unpublished observations). Furthermore, electrolytic lesion of the ventrolateral parts of the VMN blocks the induction of OTR (A. E. Johnson, C. R. Harbaugh, and R. Gelhard, unpublished observations).

The estrogen-induced OTRs are transported either along the dendrites or axons that project from VMN neurons into the IVMN (Millhouse, 1973). That is, large molecules including proteins and nucleic acids are transported within dendrites and

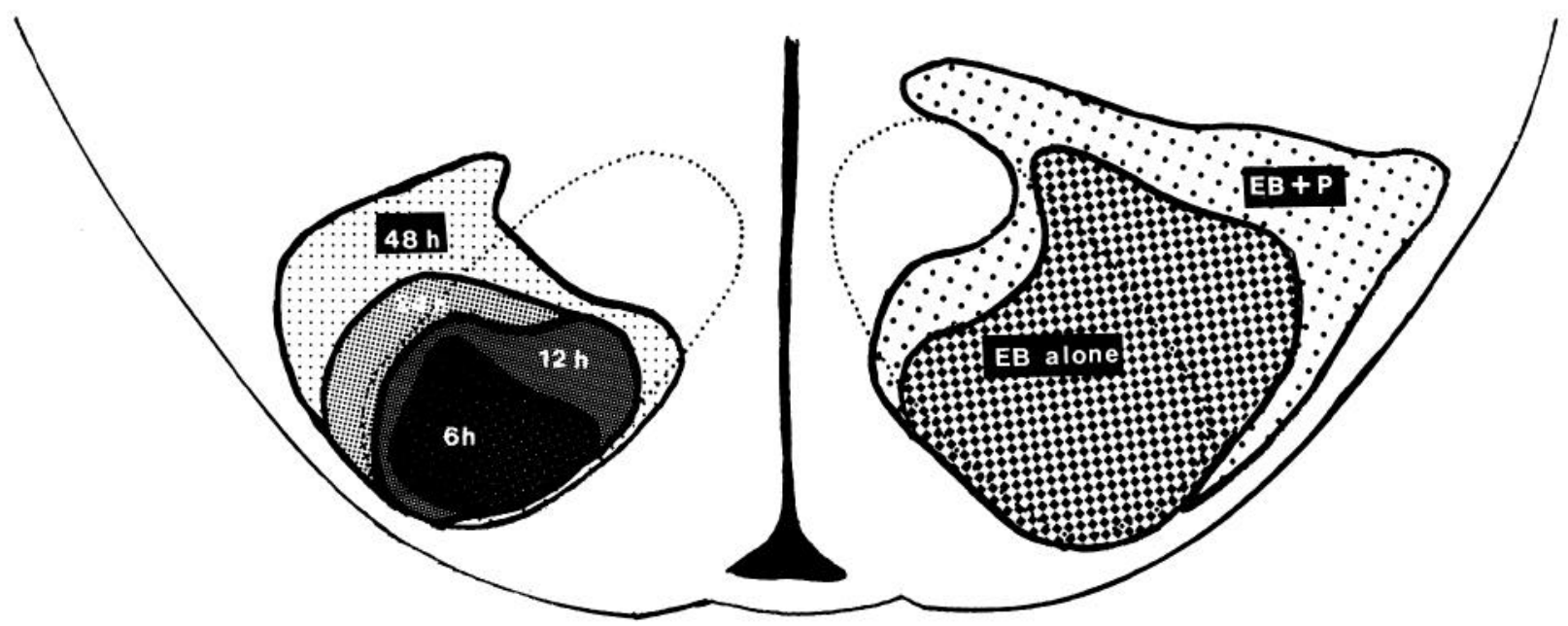

Figure 4. Distribution of oxytocin receptors in the ventromedial hypothalamus of OVX and ADX rats at different times after a single injection of $10 \mu \mathrm{g}$ of EB (left side, experiment iii) or after two successive injections of $10 \mu \mathrm{g}$ of EB, followed $48 \mathrm{hr}$ later by a third injection of vehicle (EB) or of $0.5 \mathrm{mg}$ of $\mathrm{P}(E B+P)$ (right side, experiment ii). The dotted lines delimit the VMN of the hypothalamus. After a single injection of EB, the area covered by the estrogen-induced OTRs increased progressively between 6 and $48 \mathrm{hr}$. However, even after treatment with $2 \times 10 \mu \mathrm{g}$ of EB, P was required for a maximal extension of the OTR field. 


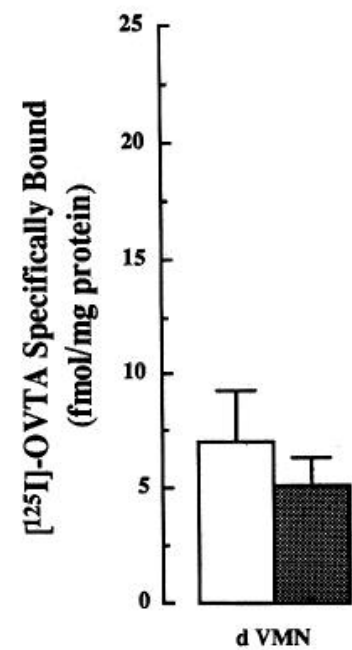

d VMN

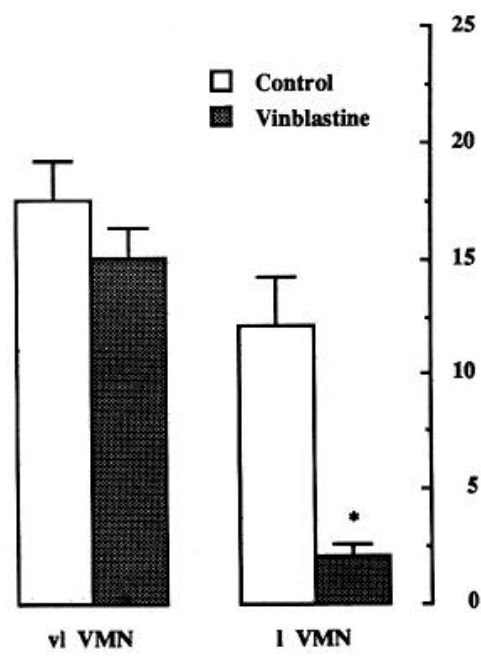

axons (Lynch et al., 1975; Laduron, 1984; Gorenstein et al., 1985; Steward et al., 1988), and neurotoxins like vinblastine or colchicine block both dendritic and axonal transport (Schubert et al., 1972; Steward et al., 1984). The time course of the spread of OTRs indicates that the rate of transport is about $500 \mu \mathrm{m} /$ $24 \mathrm{hr}$ (experiment ii), which is compatible with the speed of slow axonal transport (Schwartz, 1979) or of dendritic transport (Davis et al., 1990). As vinblastine does not block slow axonal

Figure 5. Vinblastine $(10 \mu \mathrm{g})$, when infused into the right ventromedial hypothalamus, did not prevent the induction by EB of ${ }^{125}$ I-OVTA binding within the dorsal $(d V M N)$ and ventrolateral $(v l V M N)$ subdivisions of the VMN but blocked the appearance of ${ }^{125}$ I-OVTA binding in the area lateral to the VMN ( $l V M N)$ results from three out of six animals; *, $p \leq 0.05$ when compared to the control side by paired $t$ test; for explanations, see experiment iv; means \pm SEM).

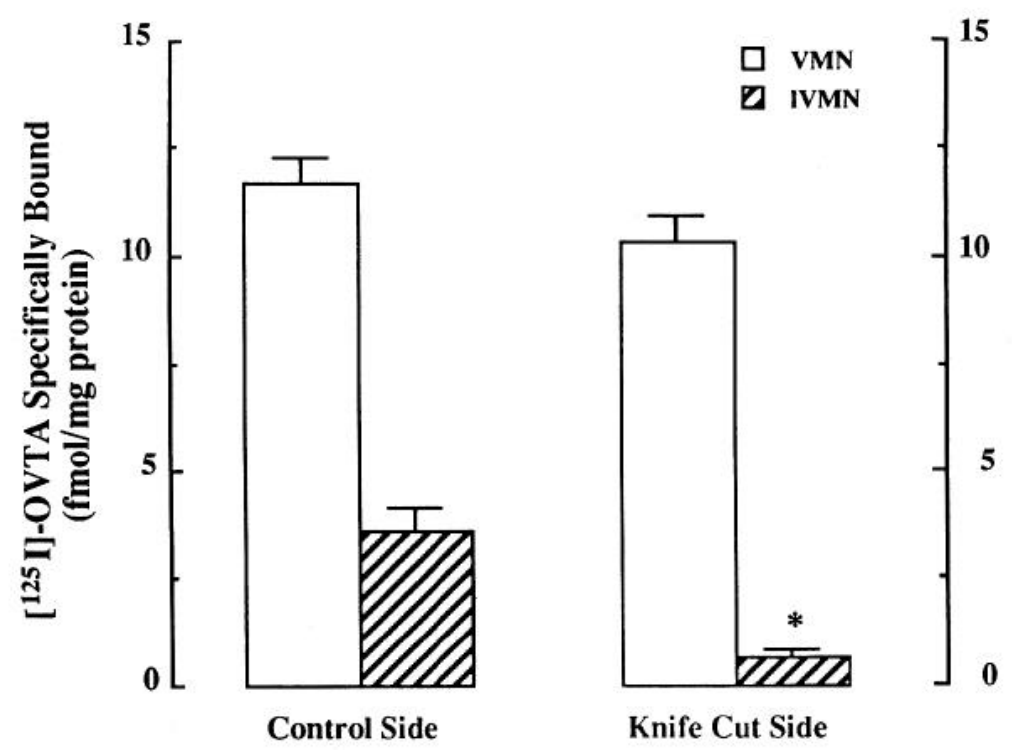

Figure 6. Top, A knife cut lateral to the right VMN prevented the appearance of ${ }^{125}$ I-OVTA binding in the area lateral to the nucleus (IVMN) but did not affect the binding of ${ }^{125}$ I-OVTA within the $\mathrm{VMN}(*, p \leq 0.05$ when compared to the IVMN of the control side by paired $t$ test; mean \pm SEM). Bottom, Representative autoradiogram showing the blockade of the spread of ${ }^{125}$ I-OVTA binding by a knife cut (arrow) lateral to the right VMN. Magnification, $\times 15$. 
transport (Schwartz, 1979; Soiefer et al., 1988), the slow rate of the OTR spread suggests that OTRs are transported along dendrites. However, as OTRs have first to be induced by estrogens and only then are transported out of the VMN, $500 \mu \mathrm{m} / 24 \mathrm{hr}$ may be a large underestimation of the real receptor flow rate.

Present findings also raise the question as to whether the lateral transport of the estrogen-induced OTR is modulated by E. A role of estrogen in the regulation of axonal or dendritic transport has never been shown and would correspond to a novel mechanism of steroid hormone action. That $\mathrm{E}$ may control the rate of receptor transport at least indirectly by modulating the concentration of OTR within the VMN is suggested by the following observations. First, the area occupied by OTRs is dependent on the amount of estrogen priming (Fig. 1). Second, the time course of the increase in density of OTRs does not parallel the time course of the extension of OTR binding (Fig. 2). This suggests that the transport of OTRs only starts after a certain density of receptors has been reached within VMN cell bodies. Thus, between 12 and $24 \mathrm{hr}$ after EB, OTR binding increased by $153 \%$ outside the VMN, but the area covered by these receptors was only enhanced by $5 \%$. Then, between 24 and $48 \mathrm{hr}$, the area covered by OTRs expanded by nearly $50 \%$, whereas binding only went up by an additional $18 \%$. Third, results of another study show that if $E$ is administered in small amounts directly to the ventromedial hypothalamus, the estrogen-induced OTRs are limited to the VMN. However, in the presence of larger amounts of E, OTRs also appear in the IVMN (Schumacher, Coirini, McEwen, unpublished observations).

However, even after priming with a high dose of EB, the action of $P$ is required for a maximal extension of the receptor field. The effect of $P$ probably reflects the activation of transported receptors because infusion of OT into the ventromedial hypothalamus only facilitates lordosis behavior if $\mathrm{P}$ is given after the estrogen priming (Schumacher et al., 1989). We recently demonstrated that the modulation of OTR binding by $\mathrm{P}$ occurs within $30 \mathrm{~min}$ of $\mathrm{P}$ administration, is not blocked by the protein synthesis inhibitor anisomycin, and can be produced in vitro (Schumacher et al., 1990a). Thus, the effects that $\mathrm{P}$ exerts on hypothalamic OTR binding correspond to a direct effect of the hormone on the receptor or on the cell membrane. P could activate and expand OTR binding either by activating silent receptors or by increasing their lateral mobility in the neuronal membrane (Schumacher et al., 1990b).

Results of a previous study show that OTRs that have been transported into the IVMN are more sensitive to $P$ than OTRs in the VMN. For example, P increases the binding of ${ }^{125}$ I-OVTA in the IVMN by $30 \%$ but only by $8 \%$ within the VMN (Schumacher et al., 1990a). These receptors may be the ones that are important for the facilitation of lordosis behavior. In support of this notion, the action of $\mathrm{P}$ is necessary for the facilitation of lordosis behavior by OT (Gorzalka and Lester, 1987; Schumacher et al., 1989). In addition, the neuronal transport inhibitor vinblastine delays the behavioral response to $P$ in estrogenprimed females (Meyerson, 1982), possibly by delaying the transport of OTRs. This raises the question of the function of the dense OTR binding within the VMN. It is possible that OTRs within the VMN may be less sensitive to $P$ than OTRs in the IVMN because they have functions other than the facilitation of female mating. Thus, OT is involved in the regulation of many other central mechanisms (Fahrbach et al., 1985; Drago et al., 1986; Argiolas et al., 1988; Arletti et al., 1989). Alternatively, OTR within the VMN may be inactive and may cor- respond to receptors that are in the process of being transported to terminals located in the IVMN, where they are subsequently activated by P. As ${ }^{125}$-OVTA is a lipophilic ligand with a high specific activity, it may label receptors at the surface of the plasma membrane as well as receptors that are transported within the intracellular compartment. Finally, the VMN may contain both types of OTR, that is, receptors that are insensitive to $\mathrm{P}$ and that are not involved in the facilitation of female mating behavior, and newly synthesized receptors that are sensitive to $P$ and that are in the process of being transported to the lVMN. This would explain the high density of OTRs in the VMN and also the slight increase of OTR binding in the VMN by P.

In conclusion, estrogens induce OTRs in the VMN. At least some of these receptors are then transported by a vinblastinesensitive mechanism into the area lateral to the nuclei where OT immunoreactivity is present within fibers and terminals. Thus, neuronal transport is a mechanism that allows the interaction between a neurotransmitter and its receptor.

\section{References}

Argiolas A, Collu M, Gessa GL, Melis MR, Serra G (1988) The oxytocin antagonist $d\left(\mathrm{CH}_{2}\right)^{5} \mathrm{Tyr}(\mathrm{Me})$-Orn ${ }^{8}$-vasotocin inhibits male copulatory behaviour in rats. Eur J Pharmacol 149:389-392.

Arletti R, Benelli A, Bertolini A (1989) Influence of oxytocin on feeding behavior in the rat. Peptides 10:89-93.

Bradford M (1976) A rapid and sensitive method for the quantitation of microgram quantities of protein utilizing the principle of proteindye binding. Anal Biochem 72:248-254.

Brown TJ, MacLusky NJ, Toran-Allerand CD, Zielinski JE, Hochberg RB (1989) Characterization of $11 \beta$-methoxy-16 $\alpha$-[ $\left.{ }^{[25} \mathrm{I}\right]$ iodoestradiol binding: neuronal localization of estrogen-binding sites in the developing rat brain. Endocrinology 124:2074-2088.

Chan SY, Worth R, Ochs S (1980) Block of axoplasmic transport in vitro by vinca alkaloids. J Neurobiol 11:251-264.

Coirini H, Johnson AE, McEwen BS (1989) Estradiol modulation of oxytocin binding in the ventromedial hypothalamic nucleus of male and female rats. Neuroendocrinology 50:193-198.

Cutts JH (1968) Protective action of diethylstilbestrol on the toxicity of vinblastine in rats. J Natl Cancer Inst 41:919-922.

Davis L, Burger B, Banker GA, Steward O (1990) Dendritic transport: quantitative analysis of the time course of somatodendritic transport of recently synthesized RNA. J Neurosci 10:3056-3068.

De Kloet ER, Voorhuis TAM, Elands J (1985) Estradiol induces oxytocin binding sites in rat hypothalamic ventromedial nucleus. Eur $\mathrm{J}$ Pharmacol 118:185-186.

Drago F, Pedersen CA, Caldwell JD, Prange AJ (1986) Oxytocin potently enhances novelty-induced grooming behavior in the rat. Brain Res 368:287-295.

Elands J, Barberis C, Jard S, Tribollet E, Dreifuss JJ, Bankowski K, Manning M, Sawyer WH (1987) ${ }^{125}$ I-labeled $\left(d\left(\mathrm{CH}_{2}\right)^{5}\left[\mathrm{Tyr}(\mathrm{Me})_{2}\right.\right.$, $\mathrm{Thr}^{4}$, Tyr- $\mathrm{NH}_{2}{ }^{9}$ ]OVT: a selective oxytocin receptor ligand. Eur J Pharmacol 147:197-207.

Fahrbach SE, Morrell JI, Pfaff DW (1985) Possible role for endogenous oxytocin in estrogen-facilitated maternal behavior in rats. Neuroendocrinology 40:526-532.

Fuchs AR, Peryasamy S, Alexandrova M, Soloff MS (1983) Correlation between oxytocin receptor concentration and responsiveness to oxytocin in pregnant rat myometrium: effects of ovarian steroids. Endocrinology 113:742-749.

Gorenstein C, Bundman MC, Lew PJ, Olds JL, Ribak CE (1985) Dendritic transport. I. Colchicine stimulates the transport of lysosomal enzymes from cell bodies to dendrites. J Neurosci 5:2009-2017.

Gorzalka BB, Lester GLL (1987) Oxytocin-induced facilitation of lordosis behaviour in rats is progesterone-dependent. Neuropeptides 10: $55-65$.

Hanson M, Edström A (1978) Mitosis inhibitors and axonal transport. Int Rev Cytol [Suppl] 7:373-402.

Harlan RE, Shivers BD, Kow LM, PfaffDW (1982) Intrahypothalamic colchicine infusions disrupt lordotic responsiveness in estrogen-treated female rats. Brain Res 238:153-167. 
Johnson AE, Coirini H, Ball GF, McEwen BS (1989a) Anatomical localization of the effects of $17 \beta$-estradiol on oxytocin receptor binding in the ventromedial hypothalamic nucleus. Endocrinology 124 207-211.

Johnson AE, Ball GF, Coirini H, Harbaugh CR, McEwen BS, Insel TR (1989b) Time course of the estradiol-dependent induction of oxytocin receptor binding in the ventromedial hypothalamic nucleus of the rat. Endocrinology 125:1414-1419.

Kelley MJ, Moss RL, Dudley CA, Fawcett CP (1977) The specificity of the response of preoptic-septal area neurons to estrogen: $17 \alpha$-estradiol versus $17 \beta$-estradiol and the response of extrahypothalamic neurons. Exp Brain Res 30:43-52.

Laduron PM (1984) Axonal transport of receptors: coexistence with neurotransmitter and recycling. Biochem Pharmacol 33:897-903.

Lessman CA (1987) Germinal vesicle migration and dissolution in Rana pipiens oocytes: effect of steroids and microtubule poisons. Cell Differ 20:239-251.

Lynch G, Smith RL, Browning MD, Deadwyler S (1975) Evidence for bidirectional transport of horseradish peroxidase. Adv Neurol 12: 297-311.

Mann DR, Barraclough CA (1973) Changes in peripheral plasma progesterone during the rat 4-day estrous cycle: an adrenal diurnal rhythm. Proc Soc Exp Biol Med 142:1226-1229.

McEwen BS (1988) Genomic regulation of sexual behavior. J Steroid Biochem 30:179-183.

McEwen BS, Davis PG, Parsons B, Pfaff DW (1979) The brain as a target for steroid hormone action. Annu Rev Neurosci 2:65-112.

McEwen BS, Coirini H, Schumacher M (1990) Steroid effects on neuronal activity: when is the genome involved? In: Steroids and neuronal activity, Ciba foundation symposium 153 (Chadwick D, Widdows K, eds), pp 3-21. New York: Wiley.

Meyerson BJ (1982) Colchicine delays the estrogen-induced copulatory response in the ovariectomized female rat. Brain Res 253:281286.

Millhouse EO (1973) The organization of the ventromedial hypothalamic nucleus. Brain Res 55:71-87.

Mobbs CV, Harlan RE, Burrous MR, Pfaff DW (1988) An estradiolinduced protein synthesized in the ventral medial hypothalamus and transported to the midbrain central gray. J Neurosci 8:113-118.

Mobbs CV, Fink G, Pfaff DW (1990a) HIP-70: a protein induced by estrogen in the brain and LH-RH in the pituitary. Science 247:14771479.

Mobbs CV, Fink G, Pfaff DW (1990b) HIP-70: an isoform of phosphoinositol-specific phospholipase C- $\alpha$. Science 249:566-567.

Nabekura J, Oomura Y, Minami T, Mizuno Y, Fukuda A (1986)
Mechanism of the rapid effect of $17 \beta$-estradiol on medial amygdala neurons. Science 233:226-233.

Nissenson R, Flouret G, Hechter O (1978) Opposing effects of estradiol and progesterone on oxytocin receptors in rabbit uterus. Proc Natl Acad Sci USA 75:2044-2048.

O'Donohue 'TL, Miller RL, Jacobowitz DM (1979) Identification, characterization and stereotaxic mapping of intraneuronal $\alpha$-melanocyte stimulating hormone-like immunoreactive peptides in discrete regions of the rat brain. Brain Res 176:101-123.

Paxinos G, Watson C (1986) The rat brain in stereotaxic coordinates. New York: Academic.

Pfaff DW, Keiner M (1973) Atlas of estradiol-concentrating cells in the central nervous system of the female rat. J Comp Neurol 151: 121-158.

Schubert P, Kreutzberg GW, Lux HD (1972) Neuroplasmic transport in dendrites: effect of colchicine on morphology and physiology of motoneurones in the cat. Brain Res 47:331-343.

Schumacher M, Coirini H, Frankfurt M, McEwen BS (1989) Localized actions of progesterone in hypothalamus involve oxytocin. Proc Natl Acad Sci USA 86:6798-6801.

Schumacher M, Coirini H, Pfaff DW, McEwen BS (1990a) Behavioral effects of progesterone associated with rapid modulation of oxytocin receptors. Science 250:691-694.

Schumacher M, Coirini H, Frankfurt M, McEwen BS (1990b) The neuronal membrane: a target for steroid hormone action. In: Hormones, brain and behavior, Vol 2 (Balthazart J, ed), pp 91-115. Basel: Karger.

Schwartz JH (1979) Axonal transport: components, mechanisms and specificity. Annu Rev Neurosci 2:467-504.

Soiefer AI, Moretto A, Spencer PS, Sabri MI (1988) Axotomy-induced ornithine decarboxylase activity in the mouse dorsal root ganglion is inhibited by the vinca alkaloids. Neurochem Res 12:1169-1173.

Soloff MS, Fernstrom MA, Periyasamy S, Soloff S, Baldwin S, Wieder $M$ (1983) Regulation of oxytocin receptor concentration in rat uterine explants by estrogen and progesterone. Can J Biochem Cell Biol 61:625-630.

Steward O, Goldschmidt RB, Sutula T (1984) Neurotoxicity of colchicine and other tubulin-binding agents: a selective vulnerability of certain neurons to the disruption of microtubules. Life Sci 35:43-51.

Steward O, Davis L, Dotti C, Phillips LL, Rao A (1988) Protein synthesis and processing in cytoplasmic microdomains beneath postsynaptic sites on CNS neurons. Mol Neurobiol 2:227-261.

Wheeler WJ, Hsu TC, Tousson A, Brinkley BR (1987) Mitotic inhibition and chromosome displacement induced by estradiol in Chinese hamster cells. Cell Motil Cytoskel 7:235-247. 